\title{
Piloting Penanggulangan Krisis Pangan Pada Masa Pandemi Covid-19 Melalui Optimalisasi Kawasan Rumah Pangan Lestari di Kelurahan Mugarsari dan Setiawargi Kota Tasikmalaya
}

\author{
Edi Fitriana Afriza ${ }^{1)}$, Andi Nur Rachman ${ }^{2)}$, Fuad Abdullah ${ }^{3)}$, Betanika Nila Nirbita ${ }^{4}$ \\ Informatika, Fakultas Teknik, Universitas Siliwangi \\ Jl Siliwangi No24, Kota Tasikmalaya, 46115, Indonesia
}

Email: edifitriana@unsil.ac.id ${ }^{1)}$, andy.rachman@unsil.ac.id ${ }^{2)}$,fuad.abdullah182@gmail.com ${ }^{3)}$, betanika@unsil.ac.id ${ }^{4)}$

\begin{abstract}
ABSTRAK
Wabah Covid-19 dan berlakunya era "New Normal" menciptakan situasi yang tentatif, apalagi dengan komoditas pangan yang terbatas bagi kebutuhan seluruh masyarakat pada masa kerawanan pangan. Produk pangan yang jumlahnya terbatas dan harganya semakin melambung tinggi di pasaran, menjadikan masyarakat memiliki solusi resistensi dari dampak pandemi Covid-19 dan era "New Normal", dengan mewujudkan kawasan rumah pangan lestari (KRPL) masyarakat ibu rumah tangga bisa mencukupi kebutuhan pangan, selain itu juga terobosan tersebut dapat memberikan suntikan perekonomian keluarga jika dikembangkan dengan komprehensif. Kegiatan akan berlangsung dengan pendekatan Asset Based Community Development (ABCD) memfokuskan pada kelompok Pemberdayaan Kesejahteraan Keluarga (PKK) yang setiap kelompoknya akan dibatasi 20 orang/ kelompok, selain itu pelaksanaan edukasi dan penyuluhan akan menerapkan protokol kesehatan sesuai dengan arahan pemerintah pusat. Diharapkan dengan terwujudnya kawasan rumah pangan lestari (KRPL) memberikan stimulus dan solusi terhadap masyarakat supaya dapat bertahan, produktif dan mandiri dalam masa pandemi ini.
\end{abstract}

Kata kunci: Pangan, Komoditas, Asset Based Community Development (ABCD).

\begin{abstract}
The Covid-19 outbreak and the enactment of the "New Normal" era created a tentative situation, especially with limited food commodities for the needs of all people during times of food insecurity. Food products are limited in number and prices are increasingly soaring in the market, making people have a solution to resistance from the impact of the Covid-19 pandemic and the "New Normal" era, by realizing a sustainable food home area (KRPL), the community of housewives can meet their food needs, in addition to It is also a breakthrough that can provide an injection to the family economy if it is developed comprehensively. The activity will take place with the Asset Based Community Development (ABCD) approach focusing on the Family Welfare Empowerment (PKK) group where each group will be limited to 20 people / group, besides that the implementation of education and counseling will apply health protocols according to the direction of the central government. It is hoped that the realization of a sustainable food house area (KRPL) will provide stimulus and solutions to the community so that they can survive, be productive and be independent in this pandemic.
\end{abstract}

Keywords: Food, Commodities, Asset Based Community Development (ABCD).

\section{Pendahuluan}

Munculnya krisis kesehatan pandemi Covid-19 menjadi bencana yang harus dihadapi oleh seluruh dunia, berbagai negara maju dan berkembang merasakan dampak krusial dari serangan wabah Covid-19 terhadap berbagai sektor, seperti kesehatan, ekonomi, serta pertanian. Sektor pertanian menjadi pusat perhatian berbagai negara dikarenakan memiliki kaitan erat dengan 
ketahanan pangan. Menurut Badan pangan dunia, Food and Agriculture Organization (FAO), memprediksi kekeringan akan melanda sejumlah wilayah di Asia setelah berangsurnya pandemi Covid-19, termasuk Indonesia. Menjadi keharusan dalam mengupayakan ketahanan pangan pada masa yang sulit seperti sekarang, untuk menghindar dari krisis pangan yang seakan menghantui Indonesia. Ketahanan pangan mengindikasikan pada ketersediaan akses terhadap sumber makanan sehingga dapat memenuhi kebutuhan dasar (Rosales \& Mercado, 2020).

Selama pandemi Covid-19 mengancam, dampak suplai logistik pangan terganggu dan keterbatasan daya beli masyarakat semakin menurun. Kondisi ini memicu kekhawatiran, Indonesia akan mengalami kerawanan pangan. Kerawanan pangan merupakan kondisi tidak tercapainya ketahanan pangan di tingkat wilayah maupun rumah tangga/ individu, (Salim dkk, 2001) dalam Ariningsih dan Rachman, 2008). Meskipun pemerintah Indonesia mengumumkan bahwa stok pangan masih mengalami surplus pada bulan Juni 2020, seperti yang digambarkan sebagai berikut:

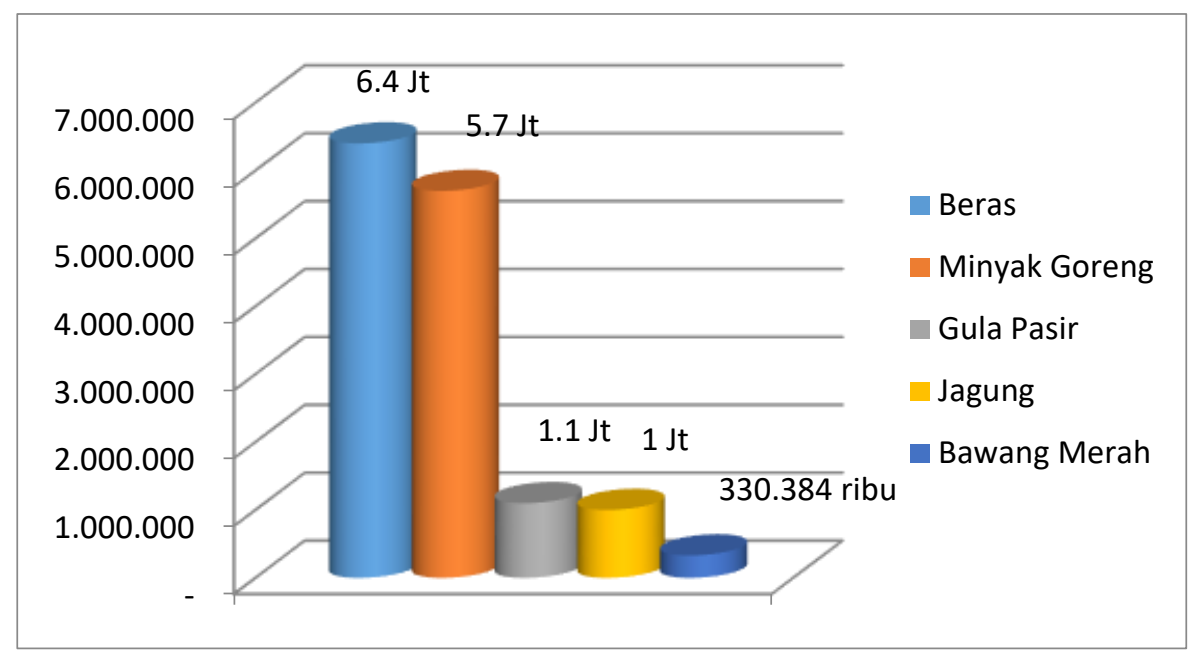

Gambar 1. Perkiraan Surplus Pangan Hingga Juni 2020 Dalam (ton). Sumber: Badan Pusat Statistik, (BPS) Kementerian Pertanian, 2020

Data gambar 1. bulan Juni 2020, Indonesia masih mengalami surplus akan tetapi seluruh elemen masyarakat harus tetap mewaspadai akan adanya krisis pangan apalagi dalam wabah Covid19 yang masih belum terdapat tanda segera berakhir. Ditambah lagi dengan adanya pemberlakuan PSBB (Pembatasan Sosial Berskala Besar), kebijakan tersebut menekankan masyarakat supaya dapat mengurangi kontak fisik dan melakukan pekerjaan dari rumah atau yang disebut Work From Home (WFH). Selain itu pola hidup masyarakat yang ikut berubah menjadikan permintaan masyarakat sebagai konsumen pangan juga berubah.

Dengan diberlakukannya "New Normal" pada awal bulan Juni 2020 masyarakat Kelurahan Setiawargi dan Mugarsari Kecamatan Tamansari Kota Tasikmalaya setidaknya harus mempersiapkan segala sesuatu yang berhubungan dengan kebutuhan rumah tangga, padahal fenomena disrupsi pasar akibat dari diberlakukannya PSBB (Pembatasan Sosial Berskala Besar) masih memiliki dampak signifikan yang mengakibatkan membuat produsen pangan terganggu penjualan. Distribusi yang terganggu akibat sehingga berdampak pada pengurangan jumlah produksi pangan di tingkat produsen, sedangkan disisi lain konsumen ibu rumah tangga di Kota Tasikmalaya berbondong-bondong mencari produk pangan menjadikan peningkatan jumlah permintaan pasokan kebutuhan akan pangan, sehingga kebanyakan produk pangan yang berada di pasar mengalami kenaikan harga seperti cabai rawit merah yang sebelumnya mencapai Rp 27.500/ kg mengalami kenaikan menjadi Rp 32.500/ kg, bawang putih dari yang semulanya Rp 25.000/ kg 
menjadi Rp 30.000/kg, sedangkan bawang merah yang harganya Rp 47.500/ kg menjadi Rp 51.000/ kg. (sumber: hargapangan.id).

Kenaikan harga pangan tersebut membuat ibu-ibu rumah tangga di kelurahan Mugarsari dan Setiawargi kerepotan dalam mengatur ekonomi rumah tangga, oleh karena itu penguatan ketahanan pangan dalam keluarga menjadi solusi dalam masa Covid-19, aktualisasi dapat berupa penciptaan kawasan rumah pangan lestari. Pemanfaatan lahan pekarangan rumah pangan lestari merupakan salah satu konsep dasar bercocok tanam dalam mengoptimalkan lahan rumah yang terbatas baik di daerah pedesaan maupun perkotaan dengan jenis tanaman yang dapat digunakan untuk kebutuhan sehari-hari. Akan tetapi ibu-ibu rumah tangga di dua kelurahan tersebut mengalami kendala, minimnya pengetahuan, keterampilan dan sarana menyebabkan sulitnya pergerakan untuk memulai dan membentuk kawasan rumah pangan lestari. Serta pandangan yang selalu keliru pada ibu-ibu rumah tangga, bahwa lahan pekarangan hanya dapat dimanfaatkan sebagai penciptaan ruang keindahan semata, akan tetapi lebih dari itu lahan pekarangan dapat menjadi penopang perekonomian bagi keluarga, setiap keluarga diharapkan dapat mengoptimalkan berbagai potensi yang tersedia termasuk pekarangan untuk dapat menciptakan ketahanan pangan berkualitas.

\section{Tinjauan Pustaka}

\subsection{Vertikultur}

Vertikultur adalah cara bertani atau bercocok tanam menggunakan media tanam dalam wadahwadah yang disusun secara vertikal (bertingkat) guna memanfaatkan ruang atau lahan terbatas. Indonesia negara dengan iklim tropis juga mulai menerapkan teknik ini karena sangat membantu kebutuhan pangan yang meningkat namun ketersediaan lahan yang menurun. Teknik penanaman secara vertikultur awalnya hanya digunakan untuk ajang pameran tanaman yang dilaksanakan di taman, kebun maupun rumah kaca. Saat ini vertikultur mulai diterapkan dirumah-rumah khususnya para ibu rumah tangga yang hobi bercocok tanam. Secara umum vertikultur digunakan untuk menanam sayuran seperti bayam, kangkung, seledri, maupun tanaman hias batang berair (Nitisapto, 1993).

\subsection{Jenis Vertikultur}

Pengertian tabulapot yang dapat digunakan untuk vertikultur yaitu gerabah, bambu, atau paralon. Jenis-jenis pot tersebut sangat cocok untuk menanam sayuran dengan batang kecil, seperti selada, sawi, kol, bunga, seledri, atau kangkung (Nitisapto, 1993).

Kegiatan vertikultur dapat memanfaatkan barang-barang bekas seperti kaleng bekas, gelas bekas air mineral, karung bekas beras dan lain-lain yang tidak dapat terurai oleh mikrorganisme. Sehingga mampu berperan aktif untuk meningkatkan nilai tambah barang bekas serta mengurangi pencemaran lingkungan oleh penumpukan sampah-sampah tersebut. Vertikultur bersifat kuat dan fleksibel untuk dipindah tempatkan. Vertikultur sebagai salah satu sistem budidaya tanaman dapat dibedakan menjadi beberapa jenis, antara lain:

1. Vertikultur Vertikal

Vertikultur vertikal biasanya menggunakan penopang yang kokoh dan berbentuk silinder yang dapat berdiri tegak pada lahan. Umumnya vertikultur jenis ini menggunakan penopang berupa paralon atau kayu yang diberdirikan tegak pada lahan, kemudian pada sisi penopang tersebut ditambahkan wadah penanaman seperti gelas bekas air mineral.

\section{Vertikultur Horizontal}

Vertikultur horizontal adalah vertikultur yang disusun secara bertingkat seperti rak atau tangga. Wadah penanaman yang digunakan dapat berupa batang pisang, rak yang dikombinasikan dengan karung bekas, kaleng bekas dan lain lain. 


\section{Vertikultur Gantung}

Vertikultur gantung adalah vertikultur yang cara peletakkan wadah penanamannya yaitu dengan digantung pada atap bangunan menggunakan tali atau kawat. Wadah penanaman biasanya berupa botol bekas, pot dan ditanami tanaman hias yang menambah nilai estetika area tersebut. Vertikultur jenis ini sering terlihat diteras-teras rumah atau perkantoran.

4. Vertikultur Susun

Vertikultur susun hampir mirip jenis vertikultur vertikal. Perbedaannya, vertikultur susun umumnya berupa pot-pot yang disusun secara vertikal tanpa penopang layaknya vertikultur vertikal.

\subsection{Manfaat Vertikultur}

Penerapan vertikultur dimasyarakat, khususnya masyarakat area perkotaan, memiliki fungsi dan beberapa manfaat (Sutarminingsih, C, 2003) seperti berikut:

1. Mewujudkan keselarasan, kesejukan, dan keindahan wilayah kota yang dominan dengan berbagai bangunan dan fasilitas umum serta padat pemukiman penduduk. Sehingga adanya vertikultur dapat meningkatkan nilai estetika daerah perkotaan.

2. Mengkonservasi sumber daya alam berupa tanah, yang dapat dilakukan dengan mengelola dan menggunakannya secara tepat dan bijak. Sehingga tanah yang ketersediaannya minimal dapat dimanfaatkan secara maksimal untuk kegunaan yang berkelanjutan.

3. Mengkonservasi sumber daya alam berupa air. Tanaman yang ditanam secara vertikultur akan lebih terkontrol secara optimal pasokan air yang dibutuhkan, karena air yang diberikan akan terserap seluruhnya oleh tanaman sampai mencapai kapasitas titik jenuh didalam wadah penanaman. Sehingga lebih hemat penggunaan air.

4. Mempengaruhi dan merombak secara mikro terhadap iklim di wilayah perkotaan, karena jumlah tanaman yang bertambah maka meningkatkan pasokan oksigen yang memberikan dampak peningkatan kesejukan wilayah tersebut.

5. Memaksimalkan pemanfaatan sampah baik organik maupun non-organik karena digunakan sebagai bahan vertikultur. Sampah organik dapat digunakan sebagai media dan pupuk tanaman, sedangkan sampah non-organik dapat digunakan sebagai wadah penanaman.

6. Membantu mengurangi pengeluaran untuk kebutuhan sehari-hari pada tingkat rumah tangga, sekaligus dapat memberikan peluang sebagai penghasilan tambahan untuk keluarga.

7. Membantu ketersediaan kebutuhan pangan seperti sayur-sayuran, buah-buahan dan lain-lain di wilayah perkotaan, yang umumnya bergantung dengan pasokan dari pedesaan. Sehingga dapat menciptakan kemandirian pangan secara mikro dan meningkatkan keterampilan masyarakat perkotaan.

\section{Metodologi Penelitian}

Kegiatan edukasi dengan memanfaatkan lahan pekarangan melalui kawasan rumah pangan lestari akan dilaksanakan di Kelurahan Mugarsari dan Setiawargi Kota Tasikmalaya bermitra dengan Pemberdayaan Kesejahteraan Keluarga PKK kelurahan. Berlangsungnya kegiatan akan tetap memperhatikan protokol kesehatan setiap kelompok PKK akan diberikan masker dan menerapkan "physical distancing". Metode yang digunakan merupakan metode yang dikhususkan untuk orang dewasa ditunjang dengan teknis yang dijalankan untuk kelancaran kegiatan ini melalui "door to door" di lahan pekarangan rumah setiap perwakilan anggota PKK.

Pemberian stimulus akan menggunakan pendekatan (ABCD) Asset Based Community Development, pendekatan ini merupakan sebuah pengembangan masyarakat yang berada dalam aliran besar mengupayakan terwujudnya sebuah tatanan kehidupan sosial masyarakat menjadi pelaku dan penentu upaya pembangunan di lingkungannya atau yang disebut dengan CommunityDriven Development (CDD), (LPPM UIN Sunan Ampel Surabaya, 2015:14). Kegiatan edukasi akan mengutamakan pemanfaatan aset dan potensi yang ada dan dimiliki oleh setiap lingkungan rumah 
anggota PKK, lahan pekarangan yang dimiliki oleh setiap keluarga merupakan aset yang berharga bagi masyarakat sekitar, sehingga dapat membantu memenuhi kebutuhan dan menopang perekonomian keluarga. Hasil pelatihan kawasan rumah pangan lestari oleh anggota PKK dapat berdampak baik untuk dapat bertahan dan berjuang di era "New Normal".

Kegiatan pelatihan dilaksanakan dengan memfokuskan pada setiap kelompok PKK berjumlah 20 orang/ kelompok, menerapkan protokol kesehatan pada saat berlangsungnya program sesuai arahan dari pemerintah. Ketua PKK dilibatkan dalam tahapan perencanaan, pelaksanaan, dan evaluasi kegiatan, diharapkan dapat memudahkan proses pelatihan.

\section{Hasil dan Pembahasan}

Pembentukan kawasan rumah pangan lestari dilatarbelakangi oleh munculnya masalah yang kompleks yang sedang dialami oleh berbagai negara terkait dengan wabah Covid-19 dan dengan diterapkannya pemberlakuan "New Normal" setidaknya akan mempengaruhi tatanan siklus ekonomi baik di tingkat produsen, distributor dan konsumen. Keterbatasan pasokan produk pangan yang megakibatkan kebanyakan anggota PKK ibu rumah tangga di Kelurahan Mugarsari dan Setiawargi mengalami kesulitan dalam memenuhi kebutuhan sehari-harinya. Dengan adanya edukasi kepada anggota PKK mengenai kawasan rumah pangan lestari diharapkan dapat mewujudkan cita-cita lingkungan keluarga bersih, sehat dan mandiri. Adapun beberapa target yang diharapkan adalah :

1. Membantu memenuhi pasokan pangan anggota PKK tangga di Kelurahan Mugarsari dan Setiawargi dalam masa pandemi Covid-19 dan era "New Normal" melalui kawasan rumah pangan lestari.

2. Memberikan kesadaran dan motivasi kepada anggota PKK untuk mengoptimalkan lahan pekarangan menjadi kawasan rumah pangan lestari supaya dapat bertahan menghadapi krisis pandemi Covid-19 dan era "New Normal".

3. Mentransferkan pengetahuan, keterampilan dan memfasilitasi sarana anggota PKK dalam bercocok tanam sehingga akan menumbuhkan gerakan pemanfaatan lahan pekarangan melalui kawasan rumah pangan lestari untuk budidaya tanaman pangan.

4. Mengembangkan kegiatan ekonomi produktif keluarga melalui kawasan rumah pangan lestari, untuk menciptakan kesejahteraan keluarga dan lingkungan hijau yang sehat dan asri secara mandiri.

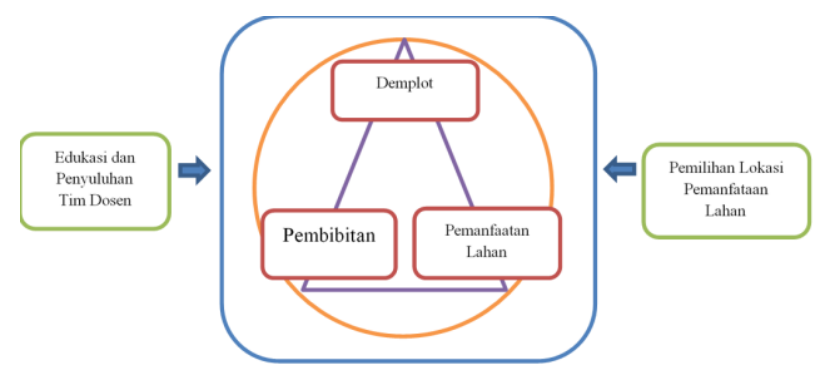

Gambar 2. Ipteks Yang Akan Ditransfer Kepada Mitra.

\subsection{Kinerja LPPM dan PPM}

Lembaga Penelitian, Pengabdian Kepada Masyarakat dan Penjaminan Mutu Pendidikan (LPPM-PMP) sebagai bagian integral dari Universitas Siliwangi berkewajiban dalam menjalankan, meningkatkan dan mengembangkan kualitas Tri Dharma Perguruan Tinggi bidang penelitian dan pengabdian kepada masyarakat. Kualitas program penelitian dan pengabdian pada masyarakat yang telah dicapai LPPM-PMP Universitas Siliwangi pada satu tahun terakhir telah mengelola 10 judul pengabdian pada masyarakat. 


\subsection{Teknik Berkebun Vertikultur}

Vertikultur merupakan gabungan dua kata yang diambil dari bahasa Inggris, yaitu vertical serta culture. Vertical memiliki arti tegak lurus, dan culture memiliki arti budidaya. Secara umum, pengertian Vertikultur adalah teknik berkebun atau bercocok tanam dengan cara bertingkat atau vertikal, yakni dari bawah ke atas dilahan yang sempit. Pada dasarnya tujuan vertikultur sendiri untuk memanfaatkan tempat atau lahan yang sempit dan terbatas dengan optimal.

Adapun jenis tanaman teknik vertikultur ialah tanaman berumur pendek atau tanaman semusim, seperti sayuran. Misalnya seledri, selada, kemangi, kangkung, sawi, bayam, serta berbagai jenis sayur lainnya. Selain tanaman sayur, juga dapat menanam cabai, tanaman obat, serta tanaman hias menggunakan teknik vertikultur.

Dalam melakukan penanaman teknik vertikultur diperlukan media sebagai berikut: 1. Pipa

Untuk melakukan teknik vertikultur, pipa besar bisa menjadi media penanaman, hanya perlu membuat lubang di sisi pipa setelah itu, isi sisi pipa dengan media tanam. Pipa disimpan secara tegak lurus, lalu tanam bibit tumbuhan, seperti sayuran maupun tanaman hias.

2. Botol Bekas

Botol bekas bisa dimanfaatkan menjadi tempat penanaman dengan teknik vertikultur. Caranya pun lebih mudah dibandingkan dengan pipa. Pada satu sisi botol dibuat lubang, setelah itu buat kembali lubang kecil pada balik sisi sebelumnya. Pada masing-masing ujung botol diberi pengikat tali, agar botol dapat digantung pada tembok. Isi botol dengan media penanaman.

Secara garis besar, penanaman teknik vertikultur dibedakan menjadi dua jenis yaitu vertikultur hidroponik, dan vertikultur konvensional.

Jenis teknik vertikultur hidroponik yaitu penanaman vertikultur menggunakan cara hidroponik. Media tanam yang digunakan bukanlah tanah, melainkan arang sekam, cocopeat, perlite dan rockwoll.

Jenis penanaman dengan teknik vertikultur konvensional yaitu menggunakan tanah sebagai media penanamannya. Teknik ini hampir sama seperti menanam dengan polybag atau pot. Model penanamannya disusun secara tegak lurus atau vertikal.

Ada beberapa syarat utama dalam penanaman dengan teknik vertikultur adalah,

1. Wadah penanaman vertikultur harus bersifat kuat, mudah dipindahkan dan tidak mudah roboh.

2. Ukuran wadah tanaman disesuaikan dengan jenis tanaman. Misalnya, gunakan pipa dengan diameter 3 inci atau botol bekas untuk menanam sayuran seperti bayam, sawi, calsim, kangkung. Sedangkan untuk tanaman seperti terong, cabai, tomat, gunakan wadah lebih besar.

3. Tempat vertikultur harus berada di luar ruangan yang terkena matahari cukup.

4. Media tanam harus bersifat gembur serta memiliki unsur hara yang cukup.
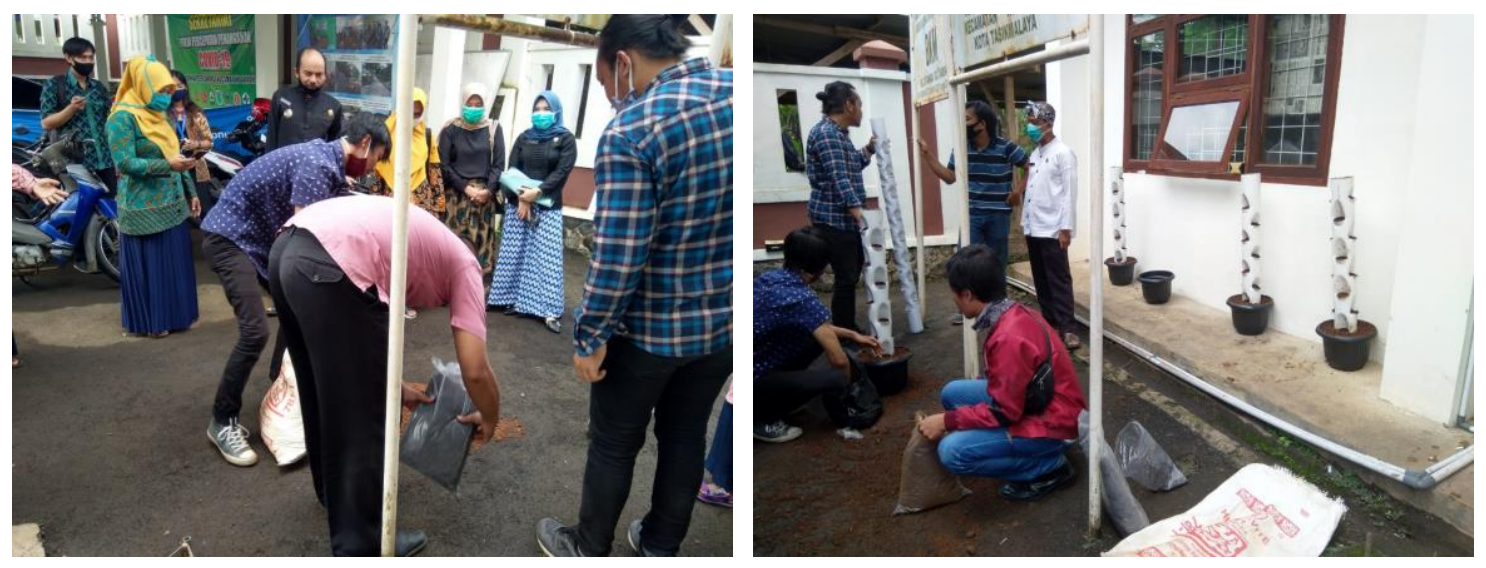

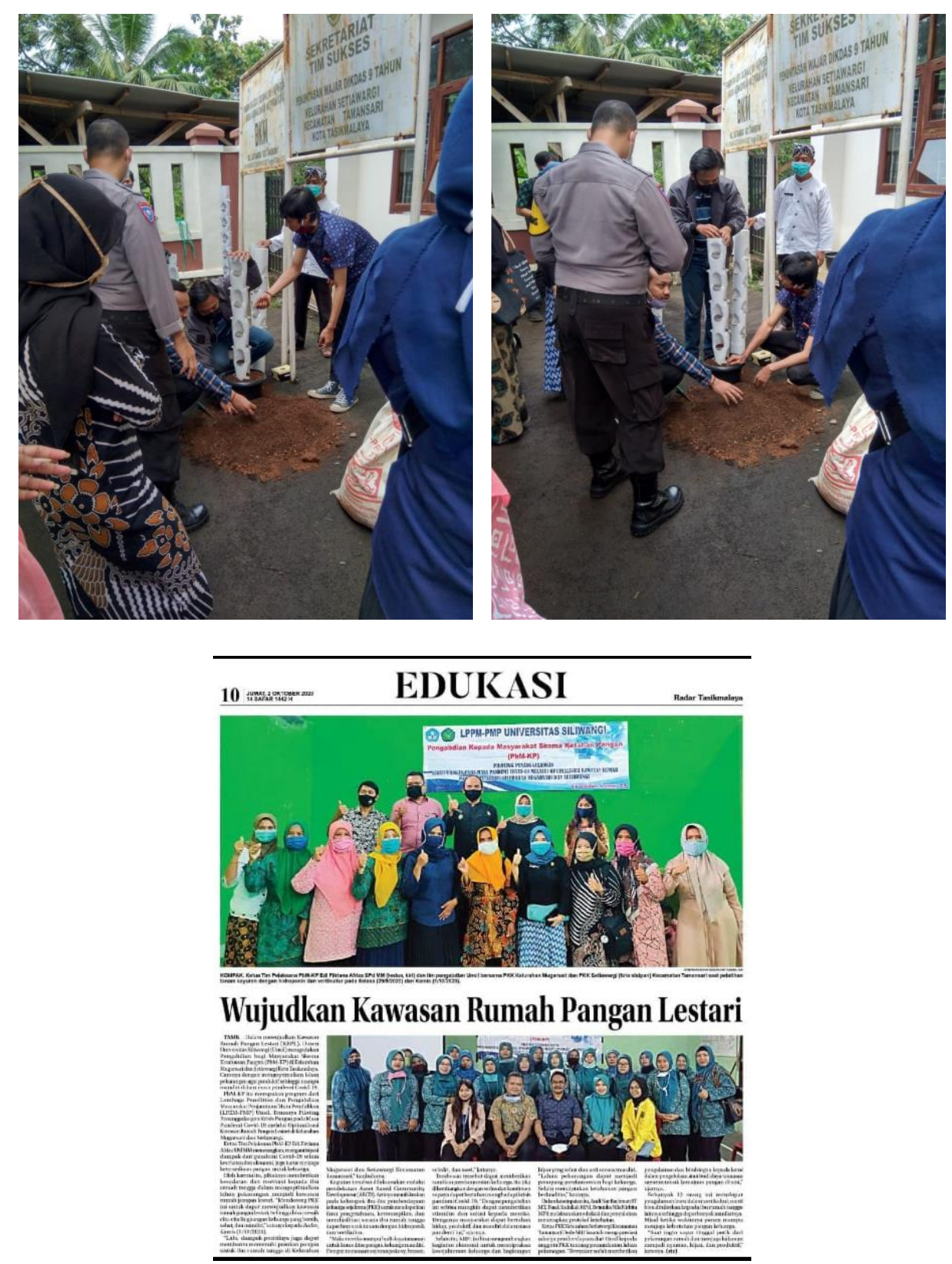

Gambar 3. Pelatihan penanaman dengan teknik Vertikultur

\subsection{Pembahasan dan Evaluasi}

Penanaman dengan teknik vertikultur adalah, tidak membutuhkan lahan yang besar, menghemat penggunaan air, usia tanaman relatif pendek dengan menanam tanaman yang bisa dikonsumsi cepat, media penanaman bisa disesuaikan berdasarkan kondisi tempat pembuatan vertikultur, perawatan tanaman lebih mudah.

Dengan memberi penanaman teknik vertikultur dilingkungan di Kelurahan Mugarsari dan Setiawargi Kota Tasikmalaya dapat membantu masyarakat untuk menanam tanaman ditempat sempit pekarangan rumah anggota PKK.

\section{Daftar Pustaka}

Ariningsih, E. Dan H.P.S Rachman. (2008). Strategi Peningkatan Ketahanan Pangan Rumah Tangga Rawan Pangan. Analisis Kebijakan Pertanian, 6 (3): 239-255. Pusat Analisis Sosial Ekonomi dan Kebijakan Pertanian. Badan Penelitian dan Pengembangan Pertanian. 
Badan Pusat Statistik (BPS) Kementrian Pertanian. (2020). Perkiraan Surplus Pangan 2020. Jakarta Pusat. Badan Pusat Statistik

BPS.(2018).Persentase Penduduk Miskin September 2017 Mencapai 10,12 Persen. Dipetik November 12, 2018, dari Badan Pusat Statistik: https://www.bps.go.id/pressrelease/2018/01/02/1413/persentase-penduduk-miskinseptember-2017-mencapai-10-12-persen.html

https://mitalom.com/teknik-vertikultur- bercocok-tanam-untuk mengoptimalkan-lahan-sempit/ http://hargapangan.id/2020/1/hargapangan juni 2020.html diakses pada tanggal (15 Juni 2020 Pukul 21.00 WIB).

Nitisapto, (1993), Budidaya Sayuran Sistem Pertanian Vertikal. Yogyakarta.

Rosales, G., and Mercado, W. (2020). Effect of changes in food price on the quinoa consumption and rural food security in Peru. Scientia Agropecuaria 11(1): 83-93

Sutarminingsih, C. (2003). Vertikultur Pola Bertanam Secara Vertikal. Yogyakarta: Kanisius.

Tim Penyusun Pedoman. (2015). Panduan KKN Asset Based Community-driven Development (ABCD). Surabaya: LP2M UIN Sunan Ampel.

Wikipedia.(2018).Daftar Negara menurut jumlah penduduk. Dipetik pada November 12, 2018, dari Wikipedia: https://id.wikipedia.org/wiki/Daftar_negara_menurut_jumlah_penduduk 